Revista Monografias Ambientais - REMOA v. 14, 2015, p. 65-78

EDIÇÃO ESPECIAL: PÓS GRADUAÇÃO EM EDUCAÇÃO,

INTERDISCIPLINARIDADE E TRANSVERSALIDADE

- UNIPAMPA - SÃO GABRIEL - RS

\title{
Pluralidade cultural: os desafios aos professores em frente da diversidade cultural
}

\author{
Fernanda Langendorf Guedes Ciliato ${ }^{1}$, Jerônimo Sartori ${ }^{2}$ \\ ${ }^{2}$ Licenciada em Letras pela Universidade da Região da Campanha - URCAMP. Pós-graduada no curso de \\ Especialização em Educação: Interdisciplinaridade e transversalidade. Universidade Federal do Pampa- \\ UNIPAMPA, Campus São Gabriel. E-mail: fernanda 1 g@yahoo.com.br. \\ ${ }^{3}$ Dr. em Educação pelo PPGEdu/Faced/UFRGS. Professor da UFFS, Campus Erechim. \\ jetori55@yaho.com.br
}

\begin{abstract}
Resumo
Este artigo aborda a importância de trabalhar na escola com os Temas Transversais, de modo que contribua para a formação de um cidadão ético e responsável, sobretudo, em relação à pluralidade cultural. Acredito que esta temática colabora para a formação de um cidadão, capaz de agir e pensar de maneira respeitosa em frente das diversidades, começando pelo espaço escolar e na sequência estender-se ao espaço social mais amplo - a sociedade.
\end{abstract}

Palavras-chave: Temas Transversais. Diversidade cultural. Prática pedagógica.

\begin{abstract}
This article discusses the importance of working at a school with Transversal themes in order to contribute to the formation of an ethical and responsible citizen, particularly in relation to cultural diversity. I believe that this issue contributes to the formation of a citizen, enabling him to act and think in a respectful way regarding to diversity, beginning in the school environment and further extending it to a wider social space - society.
\end{abstract}

Keywords: Transversal Themes. Cultural diversity. Pedagogical practice. 


\section{Introdução}

A sociedade passa continuamente por mudanças, por transições, por evoluções e por problemas de todas as ordens. Desse modo, é necessário que o cidadão esteja apto para agir e posicionar-se de maneira crítica, perante as situações que fazem parte do seu cotidiano. É na escola que o sujeito pode melhorar sua visão acerca das problemáticas como, por exemplo, a homofobia, a xenofobia, a sexualidade, a saúde, os problemas ambientais, o consumismo, o trabalho. Pensando sobre o modo de como o sujeito pode ver e sentir o mundo, colaborar para a formação de valores e padrões de conduta foi introduzido nos Parâmetros Curriculares Nacionais (PCNs) um conjunto de Temas Transversais, que buscam "[...] uma prática educacional voltada para a compreensão da realidade social e dos direitos e responsabilidades em relação à vida pessoal e coletiva e a afirmação do princípio da participação política" (BRASIL, 1998, p. 17).

Diante do exposto, é objetivo deste artigo abordar questões relacionadas ao modo da introdução dos Temas Transversais na prática pedagógica em sala de aula, sobretudo em relação à pluralidade cultural, foco deste estudo. Cabe-nos ressaltar, que a problemática do multiculturalismo está despertando interesse no meio educacional, haja vista as dificuldades em tolerar diferenças no espaço da sala de aula. À escola, dessa forma, compete problematizar e refletir sobre as atitudes de intolerância e de desrespeito ao outro, em relação à sua etnia, religião, raça etc.

Ao olhar com atenção, percebemos que a multiculturalidade está, efetivamente, presente em nosso cotidiano, ou seja, ela existe muito mais do que imaginamos. As crianças são oriundas de municípios diferentes; mesmo tendo nascido no mesmo estado, apresentam traços culturais distintos, os quais são herdados da cultura indígena, africana, bem como de sujeitos vinculados às imigrações alemãs, italianas, polonesas, árabes, asiáticas, orientais e judias. Recentemente, o Brasil tem recebido uma grande quantidade de imigrantes de países da América Latina, do Leste da Ásia e da África, os quais já se encontram presentes nas salas de aula das escolas brasileiras. Com base nessa ideia, é fundamental que os alunos estejam inseridos em um universo escolar livre de ações discriminatórias que favoreça a interação entre todos os seres humanos.

Peres (2000) alerta para o fato de que apesar de se falar em educação voltada para os valores, para os direitos humanos e igualdade de oportunidades, tolerância e convivência para paz, educação inter/multicultural, educação ambiental e antirracista, o que vemos são manifestações de intolerância, marginalização, preconceito, racismo e xenofobia.

Em razão de tais questões, cabe à escola o importante papel de colaborar para que questões relacionadas à ética, saúde, meio ambiente, orientação sexual e pluralidade cultural não passem despercebidas, mas que sejam consideradas no universo escolar. É imprescindível que a comunidade escolar perceba o quanto a pluralidade cultural é rica, o quanto os aspectos relacionados à diversidade colaboram para a formação de um cidadão conhecedor de suas raízes, que reivindique seus direitos e cumpra seus deveres, que desenvolva princípios e valores morais próprios de um cidadão, de uma pessoa de bem.

A proposta dos Temas Transversais, quando adequadamente entendida, interpretada e aplicada, é relevante pelo fato de potencializar a reflexão e a crítica sobre os problemas que emergem das contradições derivadas das múltiplas matrizes culturais. O problema é que a grande maioria dos professores e da própria comunidade escolar demonstra não estar preparada e, tampouco, comprometida em trabalhar com os assuntos relativos ao multiculturalismo. Isso é recorrente pelo fato 
de que boa parte dos docentes não assume a responsabilidade de trabalhar os Temas Transversais, conforme o que se estipula nos PCNs.

Desse modo, procuramos conhecer e entender como esses temas estão sendo trabalhados em uma escola da rede municipal da região de abrangência do Campus São Gabriel, Unipampa, sobretudo, a pluralidade, sendo que na escola foco desse estudo há entre seus estudantes uma grande diversidade cultural.

A sistematização deste texto, portanto, toma como uma escola de Ensino Fundamental, em que a diversidade cultural faz parte da realidade da comunidade escolar.

\section{Metodologia do estudo}

O presente artigo é resultado de uma pesquisa qualitativa ${ }^{4}$ desenvolvida em uma escola pública municipal situada na região de abrangência do Campus São Gabriel, Unipampa, Rio Grande do Sul, que conta com duzentos e quarenta e sete alunos, entre eles quarenta e sete oriundos de assentamentos rurais. Os alunos dos assentamentos rurais são naturais das cidades de Júlio de Castilhos, Ijuí, Santana do Livramento, Santa Maria, São Sepé, Criciúma, Piratini, Jóia e Porto Alegre. A escola conta com duas turmas de Educação Infantil, nível um e nível dois, bem como turmas do primeiro ao nono ano do Ensino Fundamental.

A pesquisa procurou estimular os sujeitos da escola a expressarem o seu pensamento sobre a aplicabilidade dos temas transversais nas aulas e sobre questões relacionadas à pluralidade cultural. Para isso, foi aplicado um questionário, constituído por perguntas abertas, aos vinte e nove docentes, quatro estagiários e oito funcionários da escola. Aos alunos, foram realizadas perguntas sobre o tema, permitindo que eles expressassem livremente o seu pensamento sobre o assunto. O método buscou conhecer o "olhar" dessa escola em relação à diversidade cultural, que é bastante saliente nas salas de aula, procurando entender a forma de abordagem dos Temas Transversais, especialmente, da diversidade cultural.

Os referenciais metodológicos também contam com uma pesquisa bibliográfica, de autores como Paulo Freire, Marcos Cordiolli, Rafael Yus, Flávia Pansini e Miguel Nenevé, Tereza Almeida, Ángel Pérez Gómez, entre outros, os quais contribuíram para a obtenção de um conhecimento mais amplo sobre os Temas Transversais, possibilitando a fundamentação teórica das ideias referentes ao foco do estudo. Conta, também, com uma pesquisa documental, a qual analisa o Regimento Escolar para verificar o posicionamento da escola em relação aos Temas Transversais, especialmente, à pluralidade cultural.

No intuito de colaborar com a formação de um cidadão capaz de agir e pensar de maneira respeitosa em face da diversidade, os pesquisadores realizaram alguns momentos de reflexão e de diálogo com os alunos do $9^{\circ}$ ano da escola pesquisada. O momento contou com uma explanação sobre pluralidade cultural; na sequência, houve a exibição de vídeos sobre o tema. Por fim, lançaram-se perguntas, possibilitando ao aluno a construção do seu próprio conceito de pluralidade cultural, considerando o seu ambiente escolar.

\footnotetext{
${ }^{4}$ De acordo com Santos Filho (2001, p. 43), a pesquisa qualitativa busca a "compreensão direta ou a apreensão imediata da ação humana", considerando que "o pesquisador procura compreender a natureza da atividade em termos de significado que o indivíduo dá a sua ação".
} 
Com certeza, o nicho desta escola é apenas um "grão de areia" diante da comunidade mais ampla. Mas, a expectativa é que sirva de exemplo e de motivação para que professores e demais atores da escola pensem e ajam, tendo um olhar voltado à importância da diversidade cultural. $\mathrm{O}$ aprimoramento da visão sobre a diversidade cultural pode tornar o mundo mais interessante, considerando que as práticas culturais, que se mesclam na sociedade, contribuem para o fortalecimento das relações interpessoais.

\section{Os Temas Transversais e sua implicação para a pluralidade cultural na Escola Básica}

Pensando em questões que fazem parte da atualidade que, na maioria das vezes, são motivos de atos preconceituosos, o Ministério da Educação e Desporto acrescentou nos Parâmetros Curriculares Nacionais (PCNs) os Temas Transversais. Entre os temas, encontra-se a Pluralidade Cultural, viabilizando ao professor e à comunidade escolar trabalhar em prol de uma educação que colabore na formação de um cidadão participativo, reflexivo, conhecedor de seus direitos e deveres.

Atualmente, o papel da escola vai muito além de ensinar Matemática, Português, Ciências, História e Geografia. A escola é uma das grandes responsáveis pela formação do cidadão, preparando o educando para interagir na sociedade, de maneira ética e responsável. Para aprimorar a formação cidadã foram inseridos nos Parâmetros Curriculares Nacionais (PCNs) os Temas Transversais, tornando obrigatória a sua inclusão no currículo escolar, de forma transversal.

Por serem questões sociais, os Temas Transversais têm natureza diferente das áreas convencionais. Tratam de processos que estão sendo intensamente vividos pela sociedade, pelas comunidades, pelas famílias, pelos alunos e educadores em seu cotidiano. São debatidos em diferentes espaços sociais, em busca de soluções e de alternativas, confrontando posicionamentos diversos tanto em relação à intervenção no âmbito social mais amplo quanto à atuação pessoal (BRASIL, 1998, p. 26).

Nesse sentido, os Temas Transversais propõem uma educação mais comprometida com a cidadania do seu povo, reforçando o texto da Constituição Federal, principalmente nos artigos 1o e 2o, os quais estabelecem princípios fundamentais para viver com dignidade, igualdade e responsabilidade social. No entanto, constar nos PCNs não é suficiente para, de fato, surtir efeitos reais na sociedade. É fundamental que as mudanças e as práticas democráticas, realmente, aconteçam inicialmente no ambiente escolar, na sequência estenda-se à sociedade em geral.

Ao todo, temos sete tópicos elencados como temas transversais, sendo que cinco deles - meio ambiente, saúde, ética, pluralidade cultural e orientação sexual - são comuns tanto para os anos iniciais quanto para os anos finais do Ensino Fundamental. No grupo destinado aos anos finais também são indicados: trabalho e consumo; para os anos iniciais, ainda, estão indicados os temas locais. O objetivo da inclusão desses temas aos PCNs é o de formar um cidadão que tenha uma visão acerca de conceitos e valores fundamentais para uma boa (con)vivência em sociedade, de maneira ética e democrática.

A educação para a cidadania requer que questões sociais sejam apresentadas para a aprendizagem e a reflexão dos alunos, buscando um tratamento didático que contemple sua complexidade e sua dinâmica, dando-lhes a 
mesma importância das áreas convencionais. Com isso o currículo ganha em flexibilidade e abertura, uma vez que os temas podem ser priorizados e contextualizados de acordo com as diferentes realidades locais e regionais e que novos temas sempre podem ser incluídos (BRASIL, 1998, p. 25).

Entretanto, muito embora os Temas Transversais integrem os PCNs e abordem temas que fazem parte da realidade social, abrangendo todas as áreas do conhecimento, o que se percebe é que eles ainda são tratados de maneira superficial e descontextualizada. Na maioria das vezes, são trabalhados apenas em disciplinas específicas ou em algumas datas determinadas. Para que essa desconexão da verdade não ocorra, os professores necessitam assumir a responsabilidade de trabalhar com os temas transversais, perpassando todas as disciplinas do currículo escolar. Trabalhar com o tema meio ambiente, por exemplo, não deve ser responsabilidade apenas das disciplinas de Ciências e Biologia, nem servir de desculpa para não ser abordado na disciplina de Língua Portuguesa ou Matemática.

Nesta perspectiva, Cordiolli (2006) diz que a forma como se apresenta a dificuldade dos professores em lidar com a transversalidade é sutil, em "acordos tácitos" dos seguintes tipos: os temas de ética e da multiculturalidade pertenceriam ao campo da Geografia e da História, já os temas de saúde e orientação sexual ao campo das Ciências Naturais.

Yus (1998) diz que os temas transversais são importantes para ter um novo conceito de escola, permitindo uma educação voltada para a realidade dos alunos, tornando o aprendizado mais significativo. Isso possibilita preparar o aluno para viver e agir como um "cidadão" crítico e consciente, capaz de compreender a natureza da ação humana no mundo.

Os Temas Transversais necessitam ser trabalhados de forma contextualizada, fazendo parte do dia a dia do professor na sala de aula, tornando as aulas mais próximas da realidade do aluno. É notório que o ensino na atualidade, ainda, carrega fortes traços de um modelo de ensino "tradicional", em que o professor transmite e o aluno absorve/recebe passivamente o conhecimento. Na maioria das vezes, o professor desconsidera o conhecimento, as experiências e os sentimentos dos alunos, o que acarreta prejuízo aos educandos que, ao não analisarem a sua realidade e o seu contexto, não vislumbram possibilidades de transformar as relações sociais.

Nesse sentido, Almeida (2006) diz que a prioridade dada aos conteúdos conceituais e à rigidez de planejamento impede que as escolas estejam mais atentas e compromissadas pedagogicamente com a abordagem dos Temas Transversais. É imprescindível que os Temas Transversais, incluídos ao currículo escolar, tenham o objetivo de colaborar com a formação psíquica e social dos educandos, haja vista que quando abordados adequadamente, podem tornar as relações sociais mais respeitosas e harmoniosas, possibilitando ao aluno aprender com a realidade social que o cerca.

\section{A Multiculturalidade em frente ao universo escolar}

A escola é um ambiente no qual se encontra uma vasta miscigenação de culturas, costumes e etnias, sobretudo, quando se refere a uma escola que recebe, além dos alunos da comunidade, alunos oriundos de um assentamento rural que acolhe famílias de diferentes regiões do estado. É impossível pensar em escola sem associá-la à cultura, pois, ambas estão interligadas, dando formas ao ambiente educacional. Gonçalves e Silva (2006, p. 28) afirmam que “[...] a pluralidade cultural se coloca como um problema quando as sociedades não se representam enquanto plurais, mas como monoculturais, a partir de um referencial etnocêntrico". 
Apesar de a multiculturalidade ${ }^{5}$ estar presente desde os primórdios da história da humanidade, ela ainda é vista como algo novo, que causa certo desconforto e até conflitos no ambiente escolar. Trabalhar com alunos com costumes, etnias e valores diferentes é um desafio inerente ao cotidiano do professor, bem como de todos os sujeitos que atuam e transitam no ambiente escolar. Por conseguinte, todos precisam se dispor a rever seus conceitos e suas atitudes em relação à realidade sociocultural que permeia o ambiente escolar.

Freire (2005) já abordava a questão de professor e aluno se tornarem sujeitos de um processo em que um aprende com o outro por meio do diálogo. Diálogo este que é mediado pelas influências socioculturais presentes em cada ser e em cada lugar. No contexto escolar, a multiculturalidade existente necessita contribuir para o desenvolvimento de um aprendizado significativo, que favoreça a formação de um cidadão consciente, autônomo e emancipado.

Nesse mesmo viés, Gomes (1999) nos convida a entender a escola como um espaço de "cruzamento de culturas", onde se desenvolva um novo olhar e uma nova postura capaz de identificar as diferentes culturas que se entrelaçam no universo escolar. Isso indica que é preciso reinventar a escola, reconhecendo o que a especifica, a identifica e a distingue de outros espaços de socialização e de relações interpessoais.

De acordo com os Parâmetros Curriculares Nacionais (PCNs), o tema pluralidade cultural visa “[...] capacitar o aluno a compreender, respeitar e valorizar a diversidade sociocultural e a convivência solidária em uma sociedade democrática" (BRASIL, 1997, p. 47). Entretanto, apesar de cultura e escola estarem profundamente interligadas, de não ser algo novo, de ser proposto pelos PCNs e de ser um tema bastante discutido na atualidade, ainda assim, a multiculturalidade no ambiente escolar é vista como desafiadora, muitas vezes, geradora de conflitos. O multiculturalismo é visto de uma maneira distorcida, estando fortemente ligado a preconceitos e discriminações que, por sua vez, surgem em meio a diversidades culturais.

\section{Análise de dados: aspectos teóricos e a realidade dos sujeitos da escola}

Como já referido na metodologia deste estudo, tendo o objetivo de conhecer a realidade da escola e contrapô-la com os aspectos teóricos, optou-se por analisar o Regimento Escolar e aplicar um questionário aos professores e funcionários. Nas visitas à escola, procurou-se ouvir relatos de professores e funcionários, de forma a ter uma proximidade com a instituição e com a dinâmica das relações interpessoais entre os atores sociais que coabitam no espaço escolar.

O questionário contou com perguntas de respostas abertas e fechadas, com o objetivo de obter uma representação, a mais próxima possível da realidade daquela escola. As perguntas que apresentam respostas fechadas foram representadas por gráficos, já as que requereram respostas abertas foram analisadas, considerando o contexto em que os sujeitos respondentes se inserem.

A primeira pergunta do questionário procurou saber se:

1 - Os alunos oriundos dos assentamentos rurais apresentam dificuldades em sala de aula, tais como: comportamento, relacionamento e aprendizagem?

5 O termo "multiculturalidade" é adotado para indicar a existência de culturas diversificadas numa mesma comunidade, região ou país, considerando que nenhuma das culturas ali presentes predomine sobre as outras. 


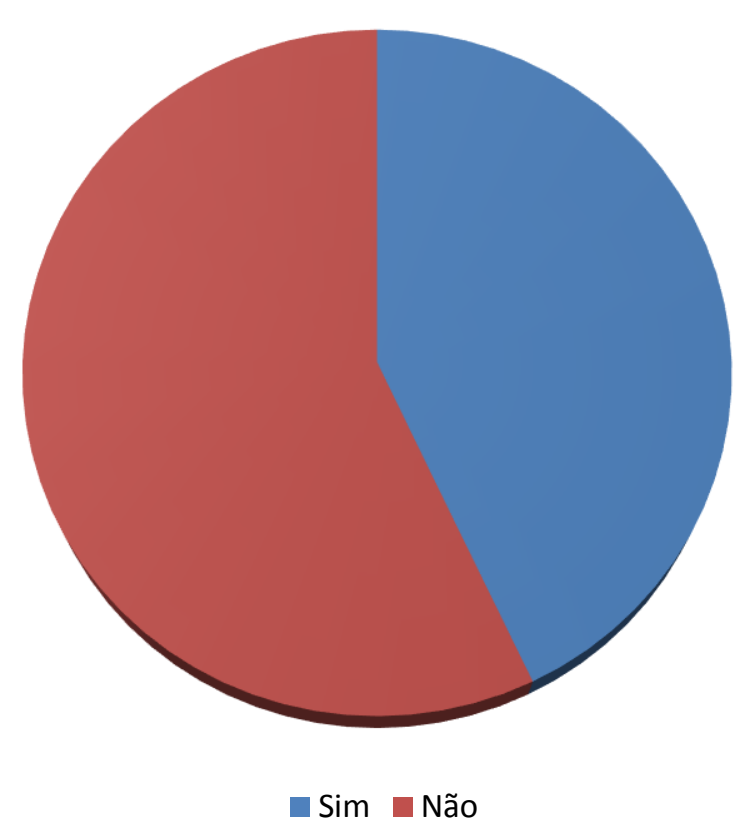

Figura 1 - Dificuldades dos alunos oriundos dos assentamentos rurais em sala de aula. Fonte: Dados primários da pesquisa, 2015.

Como podemos verificar no gráfico $57 \%$ dos professores responderam que os alunos não apresentam dificuldades em sala de aula. Já $43 \%$ responderam que os alunos apresentam alguma dificuldade.

Acompanhando a pergunta acima foi realizado o seguinte questionamento:

- Se sim, quais são as dificuldades? Se não, como é que você analisa a não apresentação de dificuldades?

A maioria dos professores que responderam "sim", registrando que a maior dificuldade encontrada é de ordem comportamental. Entretanto, alguns citaram que há falta de interesse, falta de acompanhamento dos pais em relação à realização das atividades escolares, somadas à dificuldade de compreensão das atividades propostas. Levando em consideração as respostas, essas são as maiores dificuldades apresentadas pelas crianças dos assentamentos.

Por outro lado, as professoras que responderam "não" relataram que questões comportamentais, de relacionamento e de aprendizagem são atribuídas à formação familiar, ou seja, não é pelo fato de serem dos assentamentos. Os demais consideram que o fato dos alunos estarem integrados à turma colabora para não apresentarem dificuldades no ambiente escolar. Nota-se que os docentes que responderam ao questionário, em sua maioria, atribuem à família o fato de os alunos apresentarem algumas dificuldades, seja de ordem comportamental ou de aprendizagem. De acordo com as respostas, percebemos que parece existir um distanciamento entre escola e família, e que a união destas entidades traria grandes benefícios, tanto para os alunos quanto para professores, consequentemente para toda a comunidade escolar.

Desse modo, chamamos a atenção para a tendência de culpabilização do aluno e da família; é preciso também analisar o trabalho do professor e o papel da escola, pois para Freire (2005), o professor 
que problematiza sua prática refaz caminhos, constrói situações que se adaptem à cognoscividade dos alunos.

A segunda questão do questionário aplicado aos professores foi:

2 - Existe uma integração entre os alunos naturais do município onde se situa a escola e aqueles oriundos dos assentamentos?

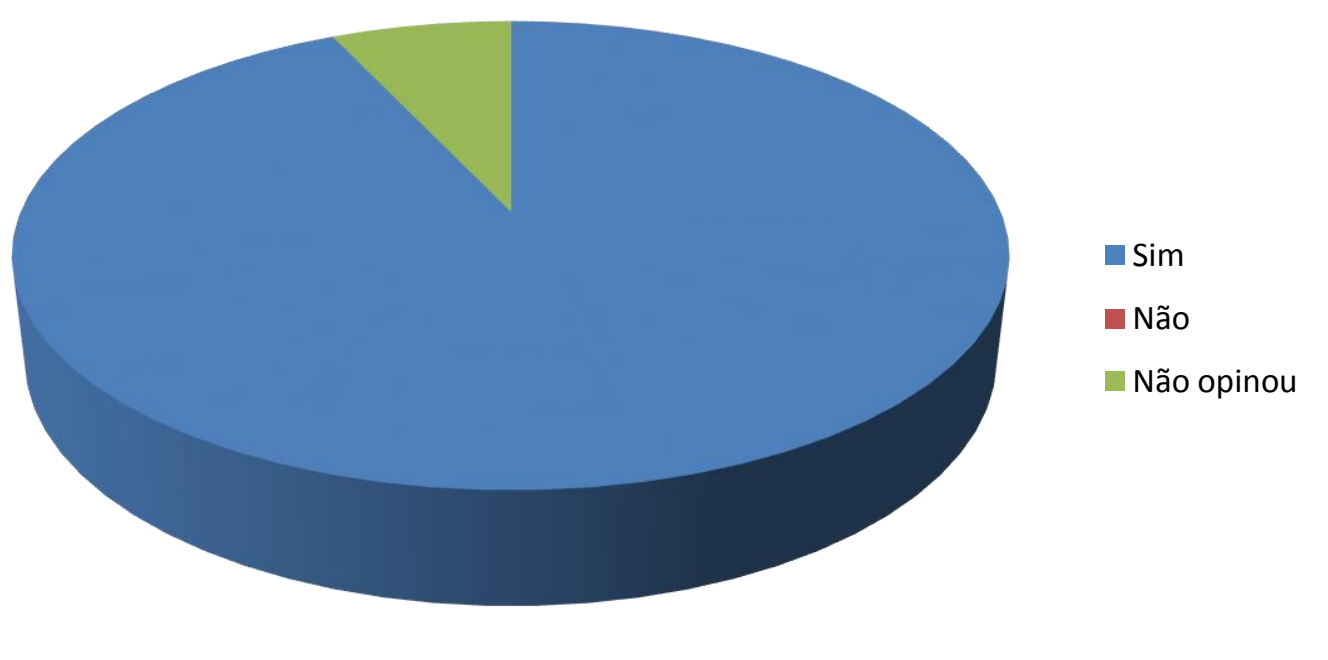

Figura 2 - Integração entre os alunos do município onde se situa a escola e os oriundos dos assentamentos Fonte: Dados primários da pesquisa, 2015.

Nesse questionamento, 93\% dos inquiridos responderam que existe integração entre os alunos, enquanto $7 \%$ não opinaram. Juntamente com a pergunta acima, o questionário contava com o seguinte questionamento:

- Como você percebe a existência ou não de integração no ambiente escolar?

Nesse questionamento, os professores ressaltaram que todos trabalham em conjunto, isto é, não fazem distinção entre os alunos oriundos dos assentamentos e aqueles naturais do próprio município em que se situa a instituição escolar.

Desse modo, pode-se concluir, a partir das respostas apresentadas, que a integração entre os alunos dos assentamentos e os naturais da comunidade escolar tem se dado de maneira positiva. Apesar das diferenças culturais, religiosas ou de etnias, a escola prevalece como um ambiente pacífico, acolhedor e rico culturalmente, contribuindo para o desenvolvimento integral do educando. Nisso reside a visão freireana de que os direitos humanos são conquistados nos embates sócio-históricos travados na sociedade e, com base nisso a democratização da educação requer dialogicidade e tratamento igual para todos.

A terceira questão de resposta fechada era:

3 - Os trabalhos em grupos são realizados de maneira em que se percebe a integração entre alunos procedentes dos assentamentos e os nascidos no município em que se situa a escola? 


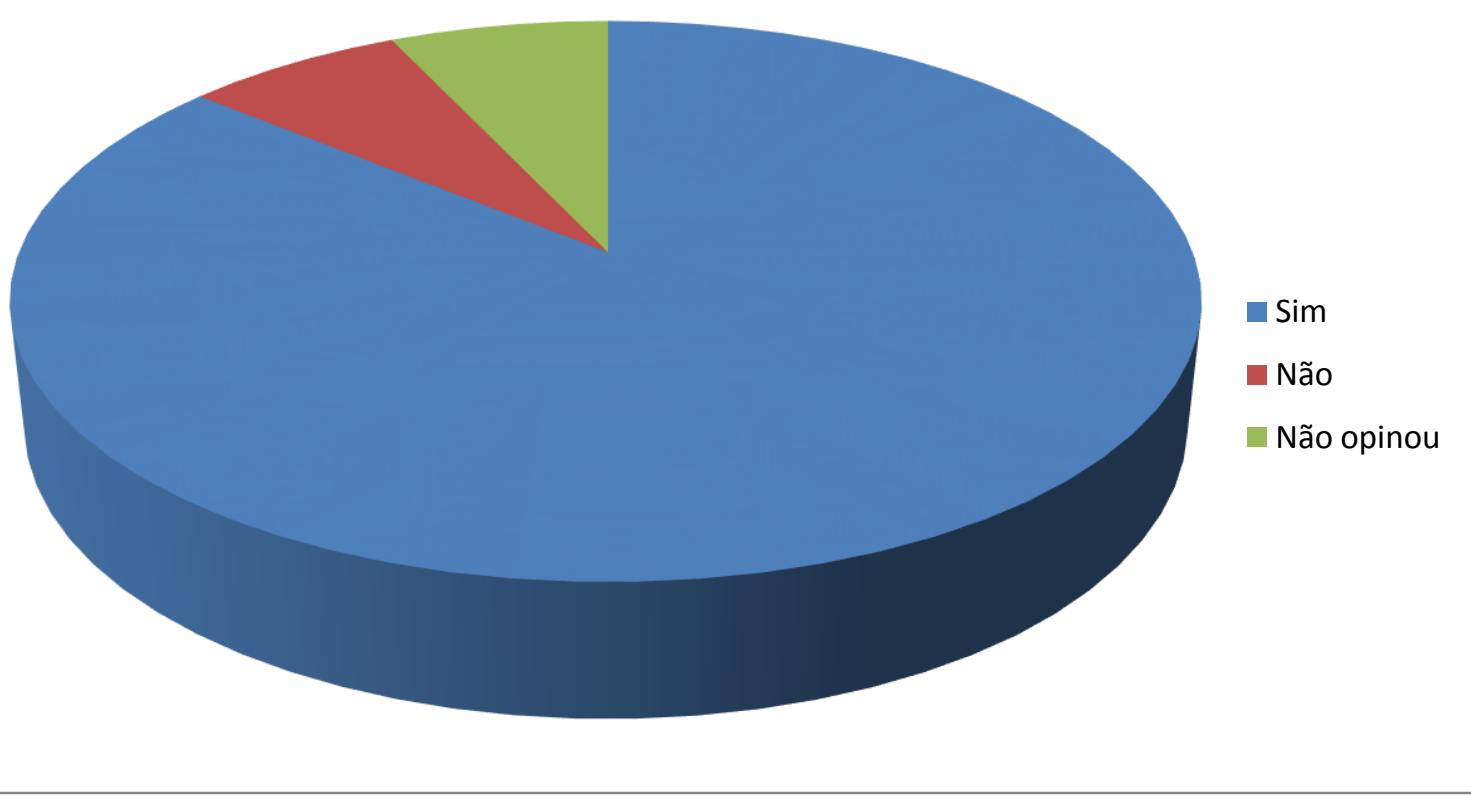

Figura 3 - Integração entre alunos procedentes dos assentamentos e os nascidos no município em que se situa a escola nos trabalhos em grupos Fonte: Dados primários da pesquisa, 2015.

Nessa pergunta, $86 \%$ dos professores responderam que os alunos realizam os trabalhos em grupos de forma integrada, 7\% responderam não haver integração e outros 7\% não opinaram.

Questionados sobre como eles percebiam a integração ou a falta desta na realização dos trabalhos em grupos, a maioria dos professores responderam que os alunos não fazem distinção entre uns e outros. Os demais, mesmo os que responderam "não", não justificaram a resposta.

Quando questionados sobre como eles abordavam os Temas Transversais na sala de aula, considerando a inclusão destes nos PCNs, as respostas apresentadas deixaram claro que a abordagem desses "Temas" é relativa, permitindo-nos concluir que muitos dos professores da escola ignoram ou não dominam o assunto. Em nenhuma das respostas houve a exposição de como os professores realmente abordam os Temas Transversais. Tampouco, se constata preocupações relacionadas com a formação crítica do aluno. Tal fato pode ser constatado nas respostas destacadas:

"[...] sempre trabalhamos valores e ética em todas as disciplinas".

“[...] geralmente são abordados em vídeos, palestras”.

“[...] até mesmo os livros 'atuais' tratam da atualidade e a vivência diária nos leva aos Temas Transversais".

"[...] os Temas Transversais são abordados naturalmente, porque se apresentam no próprio livro didático, de acordo com as séries. São direitos humanos, saúde, ambiente, relacionamento etc." (DADOS PRIMÁRIOS DA PESQUISA, 2015). 
Os depoimentos destacados nos permitem entender que o livro didático, ainda é o instrumento que embasa a ação pedagógica do professor. Assim, no momento em que se ignoram aspectos da vida cotidiana dos sujeitos na prática escolar, estar-se-á fugindo da perspectiva da educação libertadora que, de acordo com Freire (2005), se configura na esfera da problematização, do diálogo e da síntese compreensiva e crítica da realidade.

A quinta resposta aberta do questionário era:

5 - Considerando a diversidade de estudantes presentes na escola e na sala de aula, como se aborda ou se deveria abordar a questão do multiculturalismo?

A partir de algumas respostas obtidas nesta pergunta, percebe-se que a riqueza cultural presente naquela escola poderia ser mais bem valorizada e aproveitada, colaborando para a formação de pessoas livres de preconceitos, que respeitam a diversidade. Entre as respostas, algumas chamam a atenção para o que se verificar abaixo:

\footnotetext{
“[...] naturalmente".

“[...] os alunos devem ser inseridos no ambiente multicultural, sua visão de mundo deve ser ampliada, devemos prover material para que as crianças conheçam e se possível vivenciem essa diversidade cultural através da internet, leituras e passeios".

“[...] sempre procuro trabalhar de forma a integrar todos no ambiente escolar, não importando a sua origem e o meio em que vivem".

“[...] não importa a sua origem e o meio em que vivem todos devem trabalhar de forma integrada no ambiente escolar". (DADOS PRIMÁRIOS DA PESQUISA, 2015).
}

Para Oliveira e Silva (2011), trabalhar a Pluralidade Cultural ou Multiculturalismo no contexto escolar representa rever as atitudes e as práticas educacionais. Para tanto, é preciso oferecer aos alunos oportunidades para que conheçam suas origens, a sua identidade, valorizando as diferentes culturas e promovendo a construção de sua própria auto-estima.

A filosofia da escola, de acordo com o seu Regimento Escolar, diz que a escola fundamenta suas atividades na busca do resgate de valores morais, sociais e religiosos, através do diálogo com as diferenças, de solidariedade e do prazer de aprender. Entretanto, algumas das respostas não condizem com esta filosofia.

Nesse contexto, Pansini e Nenevé (2008) abordam a questão da formação multiculturalmente orientada, expondo que esta precisa ajudar o professor a dar-se conta da riqueza que perpassa na cultura do aluno, compreendendo que seu papel vai muito além de ensinar os conteúdos curriculares. Ou seja, o professor necessita questionar, principalmente, as imagens valorizadas pelo currículo, as quais nem sempre são as imagens que no contexto dos alunos devem ser valorizadas, para que eles possam contar a sua história e dizer a sua palavra.

O questionário aplicado aos demais funcionários da escola contava com a seguinte questão de resposta fechada:

- Você percebe diferenças entre os alunos procedentes dos assentamentos e os naturais de nosso município? 


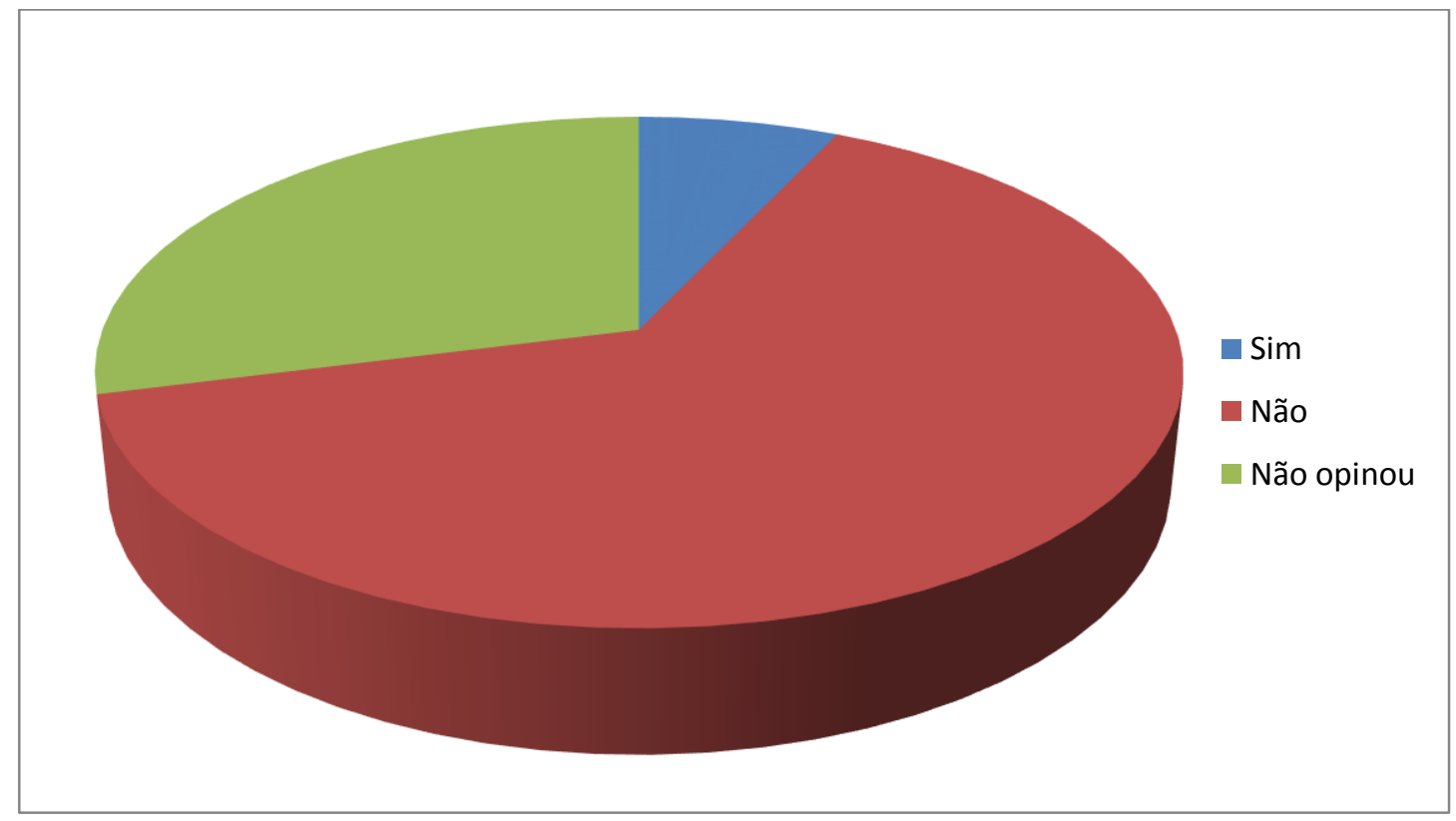

Figura 4 - Percepção dos funcionários sobre as diferenças entre os alunos procedentes dos assentamentos e os naturais de nosso município Fonte: Dados primários da pesquisa, 2015.

Nesse questionamento, $7 \%$ dos funcionários responderam que percebem alguma diferença entre alunos dos assentamentos e os naturais do município em que está localizada a escola, entretanto, não justificaram a resposta quando questionados sobre quais as principais diferenças apresentadas, $64 \%$ disseram não perceberem nenhuma diferença entre os alunos e 29\% não opinaram.

Na questão "qual é o seu olhar em relação aos alunos oriundos dos assentamentos rurais, considerando seus hábitos e atitudes?", obtiveram-se respostas como:

“[...] eu os considero igual aos outros, já que alunos com péssimo comportamento existem em todos os lugares".

“[...] não faço distinção, todos são alunos em sala de aula".

“[...] não percebemos diferenças entre assentados ou não, todos são alunos a partir do momento que estão na escola não pode, não deve existir 'rótulos".

"[...] como qualquer aluno, seus hábitos e atitudes dependem da educação recebida em casa. Na maioria são bons alunos, respeitosos, socializados".

“[...] tenho um olhar igual com todos os alunos, pois hábitos e atitudes são cultivados em casa, independentes do lugar onde moram".

"[...] não faço a mínima ideia desta "distinção", pois no momento em que estou em sala de aula todos são alunos". (DADOS PRIMÁRIOS DA PESQUISA, 2015). 
Os registros, em forma de respostas, dão a ideia de que o olhar dos atores que atuam na escola não faz diferença entre os alunos provenientes dos assentamentos e aqueles originários do próprio município em que se localiza a escola. Pansini e Nenevé (2008) defendem que a educação multicultural propõe uma ruptura com os modelos pré-estabelecidos e com as práticas ocultas que, no interior do currículo escolar, produzem um efeito de colonização em que os estudantes de diversas culturas, classes sociais, matizes étnicas, ocupam o lugar dos colonizados e marginalizados, por meio de um processo de silenciamento de sua condição de vida real.

Diante da análise, é possível perceber que a escola apresenta traços que nos fazem acreditar que ainda é necessário haver mudanças; espera-se um maior comprometimento no que refere a uma educação que procura formar de um cidadão responsável, crítico, consciente e democrático, preparado para conviver com a diversidade de maneira respeitosa, sem procurar anular a origem do outro.

\section{Sobre o processo de intervenção}

O estudo contou com a realização de momentos de diálogo e reflexão a partir de uma exposição dialogada, bem como, de uma sessão de vídeos sobre pluralidade cultural, em uma turma do $9^{\circ}$ ano, composta por alunos naturais de São Gabriel, São Sepé, Júlio de Castilhos, Santa Maria, Caçapava do Sul e São Borja.

Na sequência, lançaram-se perguntas sobre o tema, possibilitando aos alunos uma maior integração, bem como obter o posicionamento sobre a questão que trata da pluralidade cultural. As questões versaram sobre a existência da diversidade cultural na escola; sobre como esta diversidade cultural tem se apresentado no ambiente escolar; se os alunos consideram importante existir diversidade cultural; como seria se todas as pessoas fossem iguais e gostassem das mesmas coisas; por último, indagou-se sobre a questão do respeito pelas diferenças dentro do ambiente escolar.

Durante todo o período, os alunos participaram e demonstraram interesse pelo assunto. $\mathrm{Na}$ oportunidade, foi possível perceber que eles reconhecem que o respeito à diferença é fundamental para a existência de um ambiente tranquilo e harmonioso nas instituições. Em uma das perguntas, os alunos comentaram que não haveria "graça" viver em um ambiente onde todos fossem iguais, em que tivessem os mesmos hábitos e costumes. Em algumas situações os estudantes percebem a presença do preconceito em relação, principalmente, aos gostos musicais, à religião, à maneira de falar e em relação ao vestuário do outro.

Os seres humanos são seres construtores e criadores de cultura, a partir do espaço em que vivem e convivem. Portanto, tudo o que se cria nas tramas da realidade social, sempre passível de mudanças, é cultura. Assim, vivemos e interagimos na e a partir da cultura, que naturalmente é diversificada, porque é criada em locais distintos e singulares. Cabe-nos, então, destacar que os homens criam e configuram "culturas", algumas preservadas, outras modificadas para ajustá-las aos contextos sociais, políticos, econômicos e culturais.

Então, realçamos que o momento da intervenção na sala de aula foi bastante proveitoso, tanto para os pesquisadores quanto para os alunos da referida turma. Na oportunidade, foi possível perceber que apesar dos alunos não possuírem um conceito definido sobre o tema, demonstram respeitar a diversidade cultural existente na escola e na comunidade. O momento, ainda, foi importante para que eles tirassem dúvidas sobre o tema, elaborassem o seu próprio conceito dentro da sua realidade escolar e percebessem que agir de maneira preconceituosa e desrespeitosa contribui para um mundo de guerra, 
de desavenças e de sofrimentos. Então, respeitar, aceitar e conhecer as diferenças contribui para o aprimoramento e valorização da riqueza cultural do meio em que se vive.

\section{Considerações finais}

Em tempos de "mutações" é de fundamental importância que a sociedade esteja preparada para agir e posicionar-se de maneira ética, responsável, solidária, segura e comprometida com a dinâmica de todas as mudanças que acontecem na sociedade moderna.

Nesse sentido, a educação tem o importante papel de colaborar para a formação de verdadeiros cidadãos, capazes de tornar o "mundo" melhor do que tem se apresentado, livre de preconceitos e discriminações diante da diversidade, seja de ordem cultural, étnica, racial ou socioeconômica. Os Temas Transversais possibilitam aos professores incluir no dia a dia do ambiente escolar os assuntos que fazem parte da realidade local, regional e brasileira, contribuindo para a construção de uma sociedade mais justa e solidária.

O multiculturalismo é um tema que tem despertado interesse, tanto na sociedade quanto no meio escolar. Entretanto, os professores, na maioria das vezes, ainda não reconhecem a relevância da pluralidade cultural, bem como dos demais temas indicados como transversais. Nota-se que é necessário haver um maior comprometimento em relação à proposta da inclusão dos Temas Transversais no planejamento escolar, visto que esses também podem favorecer o desenvolvimento cognitivo, social e emocional dos educandos.

A partir de dados colhidos no decorrer do trabalho, percebe-se que nem sempre o ambiente escolar é aproveitado para apresentar aos alunos situações que os desafiem, permitindo-lhes uma reflexão sobre as questões relacionadas à sua vida e à sua cultura. A escola precisa tornar-se espaço que permita a valorização da diversidade cultural existente no contexto da comunidade local.

Vemos, também, que falta orientação, capacitação e formação para que os professores sintamse mais preparados e estimulados a trabalhar com os Temas Transversais, através de projetos ou mesmo durante as aulas, transversalizando as suas atividades. A proposta do Ministério da Educação é importante e tem seus méritos, porém, precisa ser realizado um trabalho voltado aos professores para que a proposta de inserir Temas Transversais no currículo escolar possa sair do papel e, de fato, fazer parte da prática pedagógica.

Levando em consideração a análise do trabalho e do contexto escolar, notamos que os alunos demonstram interesse pelos assuntos atuais e que uma metodologia diferenciada da "tradicional" chama a atenção, o que pode possibilitar o "resgate" do aluno que se encontra desmotivado pelos conteúdos do currículo trabalhado na escola. Os Temas Transversais necessitam ser aproveitados como forma de cativar e despertar o interesse dos alunos que, certamente, passarão a ver sentido naquilo que estão estudando. Ao mesmo tempo, a pluralidade cultural pode ser uma maneira de fortalecer a autoestima dos estudantes, colaborando para um aprendizado significativo e contribuindo para a formação de um cidadão consciente e autônomo.

\section{Referências}

ALMEIDA, T. J. B. Abordagem dos temas transversais nas aulas de ciências do ensino fundamental, no distrito de Rembepe, município de Camaçari-BA. Condoba-revista virtual. Salvador, v.2, n.1, p.1-13, jan/jun 2006. Disponível em: <http://revistas.unijorge.edu.br/candomba/2006v2n1/pdfs/TeresaAlmeida2006v2n1.pdf >. Acesso em: fev 2015. 
BRASIL. Ministério da Educação e do Desporto. Secretaria de Educação Fundamental. Parâmetros Curriculares Nacionais: Anos Iniciais do Ensino Fundamental. Brasília, DF, 1997.

BRASIL. Ministério da Educação e do Desporto. Secretaria de Educação Fundamental. Parâmetros Curriculares Nacionais: Terceiros e quartos ciclos do ensino fundamental - Os Temas Transversais. Brasília, DF, 1998.

CORDIOLLI, Marcos. A formação de valores e padrões de conduta na sala de aula: notas para um debate conceitual sobre transversalidade. Curitiba: A Casa de Astérion, 2006.

FREIRE, Paulo. Pedagogia do oprimido. 42. ed. Rio de Janeiro: Paz e Terra, 2005.

GOMES, A. I. P. La cultura escolar em La sociedad neoliberal. 2. ed. Morata, 1999. Disponível em: $<$ www.isp7.edu.ar/proyectos/jornadas/jor_escuela_nueva_junio_2014/perezgomezangelcap1laculturacritica.pdf>. Acesso em: 05 jun. 2015.

GONÇALVES, L. A. O.; SILVA, P. B. G. O jogo das diferenças: o multiculturalismo e seus contextos. 4. ed. Belo Horizonte: Autêntica, 2006.

OLIVEIRA, L. O. ; SILVA. F. A. Multiculturalismo: um desafio para o educador. Revista eletrônica-ICE, vol. 5, n. $1, \quad$ nov 2011.2015 Disponível <http://www.ice.edu.br/TNX/.../11/.../f6f7ad43f4059ef34b0a6b1c080dfb6e.pdf >. Acesso em: 17 jul. 2015.

PANSINI, F.; NENEVÉ, M. Educação multicultural e formação docente. Currículo sem Fronteiras. v. 8, n. $1, \quad$ p. 31-48, jan/jun 2008. Disponível em: < http://www.curriculosemfronteiras.org/vol8iss1articles/pansini neneve.pdf $>$. Acesso em: 17 jun. 2015.

PERES, A. N. (2000). Educação Intercultural: Utopia ou Realidade? (Processos de 88 pensamentos dos professores face à diversidade cultural: integração de minorias migrantes na escola). Profedições, Porto.

SANTOS FILHO, José Camilo dos. Pesquisa quantitativa versus pesquisa qualitiativa: o desafio paradigmático. In: SANTOS FILHO, José Camilo dos \& GAMBOA, Silcio Sánchez (orgs.). Pesquisa educacional: quantidade-qualidade. 4. ed. São Paulo: cortez, 2001. p. 13-59.

YUS, R.; trad. Ernani F. da Rosa. Temas Transversais: em busca de uma nova escola. Porto Alegre: ArtMed, 19. 